Hiroshi Tachikawa $\cdot$ Michio Tsuda $\cdot$ Kyuichiro Onoe Michiharu Ueno $\cdot$ Shigeharu Takagi $\cdot$ Yukito Shinohara

\title{
$\alpha-1$-Antichymotrypsin gene A1252G variant (ACT Isehara-1) is associated with a lacunar type of ischemic cerebrovascular disease
}

Received: September 21, 2000 / Accepted: October 19, 2000

\begin{abstract}
Antichymotrypsin (ACT) is a plasma protease inhibitor belonging to the serpine superfamily; it has many functions, and thus qualitative change in ACT is likely to result in specific diseases. We previously reported a variant $A \mathrm{ACT}$ (ACT Isehara-1, Met389Val, A1252G) in patients with ischemic cerebrovascular disease (CVD). The present study was designed to examine the association of the variant with ischemic CVD, in 87 patients and 397 agematched controls. We found that the frequency of the A1252G variant (ACT Isehara-1) was higher in the group with ischemic CVD than in the control group $(P=0.0397)$, which appeared to be independent of known risk factors. We subdivided the CVD group into lacunar and atherothrombotic subgroups. Further analysis by subtype of ischemic CVD showed an association of ACT Isehara-1 with lacunar infarction $(P=0.0036)$. These results suggest that ACT Isehara-1 is a new genetic risk factor for ischemic CVD, especially lacunar-type infarction, in Japan.
\end{abstract}

Key words $\alpha$-1-Antichymotrypsin · Ischemic cerebrovascular disease $\cdot$ Lacunar infarction $\cdot$ Risk factor of cerebrovascular disease $\cdot$ Plasma protease inhibitor $\cdot$ Serpine

\section{Introduction}

$\alpha$-1-Antichymotrypsin (ACT) is a plasma protease inhibitor belonging to the serpine superfamily, and has been found to have many functions in vitro (Travis and Salvesen 1983). Although the pathological and physiological roles of ACT

H. Tachikawa $\cdot$ K. Onoe $\cdot$ S. Takagi $\cdot$ Y. Shinohara $(\triangle)$

Department of Neurology, Tokai University School of Medicine, Isehara, Kanagawa 259-1193, Japan

Tel. +81-463-93-1121 ext. 2241; Fax +81-463-94-8764

e-mail: yshinoh@is.icc.u-tokai.ac.jp

M. Tsuda $\cdot$ M. Ueno

Department of Molecular Life Science, Tokai University School of

Medicine, Kanagawa, Japan are not established, it seems likely that qualitative change in ACT would result in specific diseases. We previously reported that a variant $A$ ACT (ACT Isehara-1, Met389Val, A1252G) was found frequently in patients with cerebrovascular disease (CVD) (Tsuda et al. 1992a). The present study was designed to examine whether there is a direct association between ACT Isehara-1 and a particular subtype of symptomatic ischemic CVD.

\section{Patients and methods}

Informed consent was obtained from all subjects prior to their inclusion in the study. We studied 87 subjects with documented CVD from Tokai University Hospital, and 397 age-matched control subjects from the HIMEDIC Imaging Center at Lake Yamanaka. All subjects were Japanese, and were selected on the basis of clinical manifestations, history of CVD, and magnetic resonance imaging (MRI) findings. Subjects who were asymptomatic but had undifferentiated bright objects or any kind of hyperintensities on their MRI T2 images were excluded from the control group. We subdivided the patients with symptomatic ischemic CVD into atherothrombotic and lacunar subgroups according to the classification of CVD in the report of The National Institute of Neurological Disorders and Stroke (Whisnant et al. 1990). Atherothrombotic infarction occurs with atherosclerosis involving selected sites in extracranial and major intracranial arteries. The term "lacunar-type" infarction is commonly used as a clinical category for the small lesions that result from the involvement of deep, small, penetrating arteries. Subjects with cardiogenic cerebral embolism and cardiac diseases, including atrial fibrillation and rheumatic heart disease, were excluded from this study, thereby eliminating specific cardiac and systemic factors.

The data were analyzed by Fisher's exact test, and in part by the Mann-Whitney $U$-test.

Genomic leukocyte DNA was used for DNA analyses, including polymerase chain reaction-single strand conformation polymorphism (PCR-SSCP) and PCR-restriction 
fragment length polymorphism (PCR-RFLP), and DNA sequencing, as described previously (Tsuda et al. 1992a; 1992b).

The PCR primers used were:

5'-TTACTGAGAGCCCCACTGCATGAT-3' and 5'-CATAAGGCTGTGCTTGATGTA-3'

PCR conditions. The PCR conditions were $94^{\circ} \mathrm{C}$ for $2 \mathrm{~min}$ to denature the DNA, then 30 cycles of $94^{\circ} \mathrm{C}$ for $1 \mathrm{~min}, 72^{\circ} \mathrm{C}$ for $2 \mathrm{~min}$, and finally, $72^{\circ}$ for $5 \mathrm{~min}$. PCR-SSCP and PCRRFLP analyses were used to identify mutation.

PCR-SSCP analysis. Primers labeled at the $5^{\prime}$-end with ${ }^{32} \mathrm{P}$ were used for $30 \mathrm{PCR}$ cycles. The PCR product labeled was diluted to 20 times its volume with $0.1 \%$ sodium dodecylsulfate and $10 \mathrm{mM}$ ethylenediamine-tetraacetic acid (EDTA). Then this solution was diluted to twice its volume with $95 \%$ formamide, $20 \mathrm{mM}$ EDTA, $0.1 \%$ bromophenol blue, and $0.1 \%$ xylene cyanol, and the resulting solution was heated in a boiling water bath for $3 \mathrm{~min}$. The denatured PCR product was applied to $6 \%$ polyacrylamide gel containing $10 \%$ glycerol, and electrophoresed at room temperature.
PCR-RFLP analysis. The PCR product (234-bp) was digested with BSPHI (New England Biolabs, Inc., Beverly, MA, USA) at $37^{\circ} \mathrm{C}$ for $2 \mathrm{~h}$. The digestion products were separated by $20 \%$ polyacrylamide gel electrophoresis and detected using ethidium bromide. The PCR digestion products from the native $A C T$ gene showed fragments of 64 and $170 \mathrm{bp}$, while the A-to-G mutation (ACT Isehara-1) should result in no change of the molecular size by restriction enzyme treatment because of the loss of the cleavage site. To confirm the polymorphism, DNA sequencing was also used.

\section{Results and discussion}

Eleven of the 87 patients with ischemic CVD, and 24 of the 397 control subjects were heterozygotes with the ACT Isehara-1 gene (Table 1). No homozygote was observed in this study. The frequency of ACT Isehara-1 (heterozygote) in the ischemic CVD group (12.6\%) was higher than that in the control group $(6.0 \%)$, and the difference was significant $(P=0.0397$; odds ratio, $2.25 ; 95 \%$ confidence interval $[\mathrm{CI}]$, 1.06-4.79). The etiology of CVD involves both environmen-

Table 1. Prevalence of risk factors for ischemic CVD

\begin{tabular}{llllr}
\hline & $\begin{array}{l}\text { CVD group } \\
(n=87)\end{array}$ & $\begin{array}{l}\text { Control group } \\
(n=397)\end{array}$ & $\begin{array}{l}\text { Odds ratio } \\
(95 \% \text { CI })\end{array}$ & \multicolumn{1}{c}{ NS $^{\mathrm{a}}$} \\
\hline Age (years; mean \pm SD) & $58 \pm 13$ & $56 \pm 8$ & & \\
Sex (\% male) & 63.2 & 69.0 & & \\
ACT Isehara-1 and risk factors & & & $2.25(1.06-4.79)$ & 0.0397 \\
$\quad$ ACT Isehara-1 (heterozygote) (\%) & 12.6 & 6.0 & $4.66(2.81-7.71)$ & $<0.0001$ \\
Hypertension (\%) & 70.1 & 33.5 & $2.08(1.15-3.76)$ & 0.0235 \\
Diabetes (\%) & 21.8 & 11.8 & $0.77(0.46-5.08)$ & NS \\
Hyperlipidemia (\%) & 31.0 & 37.0 & \\
\hline
\end{tabular}

Data were analyzed by Fisher's exact test, and, in part, by the Mann-Whitney $U$-test. Fisher's exact test was used to compare the values for the CVD group and the control group

CVD, Cerebrovascular disease; NS, not significant $(P>0.05)$; CI, confidence interval

${ }^{\text {a }}$ Mann-Whitney $U$-test

Table 2. Association of ACT Isehara-1 with other CVD risk factors in control subjects and CVD patients

\begin{tabular}{|c|c|c|c|c|}
\hline & \multicolumn{2}{|c|}{ ACT Isehara-1 gene } & \multirow[b]{2}{*}{ Odds ratio $(95 \% \mathrm{CI})$} & \multirow[b]{2}{*}{$P$} \\
\hline & With & Without & & \\
\hline Control subjects ${ }^{\mathrm{c}}$ & $(n=24)$ & $(n=373)$ & & \\
\hline Hypertension $(n=133)$ & 4 & 129 & $0.38(0.13-1.13)$ & $\mathrm{NS}^{\mathrm{a}}$ \\
\hline Diabetes $(n=47)$ & 3 & 44 & $1.07(0.31-3.73)$ & $\mathrm{NS}^{\mathrm{a}}$ \\
\hline Hyperlipidemia $(n=147)$ & 13 & 134 & $2.11(0.92-4.84)$ & $N S^{a}$ \\
\hline CVD patients ${ }^{c}$ & $(n=11)$ & $(n=76)$ & & \\
\hline Hypertension $(n=61)$ & 8 & 53 & $1.15(0.28-4.76)$ & $\mathrm{NS}^{\mathrm{a}}$ \\
\hline Diabetes $(n=19)$ & 0 & 19 & b & $\mathrm{b}$ \\
\hline Hyperlipidemia $(n=28)$ & 1 & 27 & $\mathrm{~b}$ & $\mathrm{~b}$ \\
\hline
\end{tabular}

Fisher's exact tests were used to compare each risk factor in controls with ACT Isehara-1 and native AACT genes

NS, Not significant $(P>0.05)$

${ }^{a}$ Fisher's exact test

${ }^{\mathrm{b}}$ Number of patients was too small for statistical analysis

${ }^{\mathrm{c}}$ Some subjects had more than one risk factor 
Table 3. Frequency of ACT Isehara-1 compared in CVD subgroups and control group

\begin{tabular}{llll}
\hline & $\begin{array}{l}\text { Subjects with ACT Isehara-1 } \\
\text { (number of subjects) }\end{array}$ & Odds ratio (95\% CI) & $P$ \\
\hline $\begin{array}{l}\text { Control group }(n=397) \\
\text { Subgroups of ischemic CVD }(n=87)\end{array}$ & $6.0 \% \quad(n=24)$ & 1.0 & \\
$\quad \begin{array}{l}\text { Lacunar }(n=38) \\
\text { Atherothrombotic }(n=49)\end{array}$ & $\begin{array}{l}21.1 \%(n=8) \\
\text { 6.1\% }(n=3)\end{array}$ & $\begin{array}{l}4.14(1.71-10.02) \\
1.01(0.29-3.50)\end{array}$ & 0.0036 \\
\hline
\end{tabular}

Fisher's exact test was used to compare the frequency of ACT Isehara-1 in lacunar infarction and atherothrombotic infarction patients with that in control subjects

tal and genetic factors, particularly hypertension, diabetes, and hyperlipidemia. In this study, hypertension and diabetes, but not hyperlipidemia, were associated with CVD. One must consider the possibility that ACT Isehara-1 is associated with these risk factors, and, hence, with lacunar infarction. However, no direct relation of ACT Isehara-1 with these risk factors was found by statistical analyses in either control or CVD subjects in this study (Table 2). In analysis by subtype of CVD, the frequency of ACT Isehara1 in patients with lacunar infarction was $21.1 \%$, while in patients with atherothrombotic cerebral infarction, it was only $6.1 \%$, which was similar to that in the control group (Table 3). These results indicate an association of ACT Isehara-1 with lacunar infarction $(P=0.0036$; odds ratio, $4.14 ; 95 \%$ CI, 1.71-10.02) and suggest that ACT Isehara-1 is a new genetic risk factor for ischemic CVD, especially lacunar infarction. The significance of ACT Isehara-1 (Met389Val) priority is not yet determined; however, it is known that ACT Isehara-1 has normal inhibitory activity for proteases such as chymotrypsin and cathepsin G. Determination of this ACT genotype may be useful in the assessments of risk for CVD, which could, in part, contribute to the prevention of this ailment.
Acknowledgments This study was supported in part by a Grant-in-Aid for Scientific Research from the Ministry of Education, Science, and Culture of Japan. We thank Dr. Masahiro Yamamoto and Dr. Sari Sekiyama for their advice. We also thank the staff of HIMEDIC Imaging Center at Lake Yamanaka for assistance in collecting samples.

\section{References}

Travis J, Salvesen GB (1983) Human proteinase inhibitors. Ann Rev Biochem 52:655-709

Tsuda M, Sei Y, Yamamura M, Yamamoto M, Shinohara Y (1992a) Detection of a New mutant $\alpha$-1-antichymotrypsin in patients with occlusive cerebrovascular disease. FEBS Lett 304:66-68

Tsuda M, Sei Y, Matsumoto M, Kamiguchi H, Yamamoto M, Shinohara Y, Igarashi T, Yamamura M (1992b) $\alpha-1-$ Antichymotrypsin variant detected by PCR-single strand conformation polymorphism (PCR-SSCP) and direct sequencing. Hum Genet 90:467-468

Whisnant JD, Basford JR, Bernstein EF, Cooper ES, Dyken ML, Easton JD, Little JR, Marler JR, Millikan CH, Petito CK, Price TR, Raiche ME, Robertson JT, Thiele B, Walker MD, Zimmerman RA (1990) Special report from the National Institute of Neurological Disorders and Stroke: classification of cerebrovascular diseases III. Stroke 21: 637-676 